EPJ Web of Conferences 103, 09005 (2015)

DOI: $10.1051 /$ epjconf/ 201510309005

(C) Owned by the authors, published by EDP Sciences, 2015

\title{
Photodynamic Processes in Fluoride Crystals Doped with $\mathrm{Ce}^{3+}$
}

\author{
V.V. Pavlova , V.V. Semashko, R.M. Rakhmatullin, and S.L. Korableva \\ Kazan Federal University, 18 Kremlyovskaya Str. Kazan 420008, Russia
}

\begin{abstract}
Integrated studies of photoelectric phenomena and their associated photodynamic processes in $\mathrm{LiCaAlF}_{6}, \mathrm{LiLuF}_{4}, \mathrm{LiYF}_{4}, \mathrm{LiY}_{0,5} \mathrm{Lu}_{0,5} \mathrm{~F}_{4}, \mathrm{SrAlF}_{5}$ crystals doped with $\mathrm{Ce}^{3+}$ ions have been carried out using the combination of the methods of optical and dielectric spectroscopy. The numerical values of the basic parameters of photodynamic processes and their spectral dependence in $240-310 \mathrm{~nm}$ spectral range are evaluated. It has been shown that the most probable process, which leads to the photoionization of $\mathrm{Ce}^{3+}$ ions in $\mathrm{LiY}_{x} \mathrm{Lu}_{1-x} \mathrm{~F}_{4}: \mathrm{Ce}^{3+}$ $(\mathrm{x}=0 ; 0,5 ; 1)$ and $\mathrm{LiCaAlF}_{6}: \mathrm{Ce}^{3+}$ crystals, is excited-state absorption to the states of mixed configurations of $\mathrm{Ce}^{3+}$ ions localized near/in the conduction band of crystal.
\end{abstract}

Keywords: photoionization of impurity ions, optical spectroscopy, dielectric spectroscopy

Search for the solid-state active media for UV and VUV lasers has shown that the most technically simple method of obtaining tunable UV laser action is to use parity allowed $4 f^{n-1} 5 d-4 f^{n}(5 d-4 f)$ interconfigurational transitions of trivalent cerium ions, doped into wideband dielectric crystals. However, the majority of solid-state active media experience degradation of optical and laser properties under UV excitation due to the excited-state photoionization of impurity ions, accompanied by the photoconductivity effect $(\sigma)$ and color center formation [1].

Dielectric spectroscopy, which studies variations of the complex permittivity $\left(\varepsilon=\varepsilon_{1}-j \varepsilon_{2}\right)$ of crystals under optical irradiation, is the powerful instrument for research of the photoionization processes in crystals. For instance, the variation of its imaginary part $\left(\delta \varepsilon_{2}\right)$ can be caused by the appearance of free charge carriers generated as a result of one- or multi-photon impurity ionization $\left(\delta \varepsilon_{2} \sim \sigma\right)$. On the other hand, the variation of real part $\left(\delta \varepsilon_{1}\right)$ is associated with a change of dielectric polarization of crystal due to the electronic transitions of impurity ions and color centers.

There are two widely held methods of dielectric spectroscopy which make it possible to investigate the photoionization processes. One of them is a conventional technique based on the photocurrent registration by means of blocking electrodes [2]. The second one is a microwave resonant technique based on the measurements of parameters of the cavity resonator with sample [3]. Study revealed that the signal registered by the conventional technique includes information about the variations of both parts of complex permittivity and there is no way to separate them. It creates difficulties in obtaining and interpreting the photoconductivity spectrum. The most informative method for research of the photoionization processes is a microwave resonant technique, because it allows us to study timing and spectral characteristics of each parameter $\delta \varepsilon_{1}$ and $\delta \varepsilon_{2}$ individually.

\footnotetext{
${ }^{\mathrm{a}}$ Corresponding author: Vitaly.V.Pavlov@gmail.com
} 
Moreover, in this case we can realize nanosecond temporal resolution for the study of photodynamic processes.

In this work the microwave resonant technique was applied to study of impurity photoionization in $\mathrm{Ce}: \mathrm{LiCaAlF}_{6}, \mathrm{Ce}, \mathrm{Yb}: \mathrm{LiY}_{\mathrm{x}} \mathrm{Lu}_{1-\mathrm{x}} \mathrm{F}_{4}(\mathrm{x}=0,0.5$ and 1$)$ and $\mathrm{Ce}, \mathrm{Yb}: \mathrm{SrAlF}_{5}$ crystals. Timing and spectral characteristics of the complex permittivity of the investigated crystals under laser irradiation in $240-$ $310 \mathrm{~nm}$ spectral range are investigated. The lifetime of free charge carrier is estimated. The photoconductivity spectra for all investigated crystals have been determined. Interpretation of obtained spectra was carried out using the results of pump-probe experiments. The simplified model of photodynamic processes proposed in [4] has been used for data processing and calculation of the basic parameters: photoionization spectra of $\mathrm{Ce}^{3+}$ ions, color center photoionization spectra, photoelectrons recombination cross-section and photoelectrons capture cross-section by the defects of crystal lattice. It was found that photoconductivity of $\mathrm{Ce}: \mathrm{LiCaAlF}_{6}, \mathrm{Ce}, \mathrm{Yb}: \mathrm{LiY}_{\mathrm{x}} \mathrm{Lu}_{1-\mathrm{x}} \mathrm{F}_{4}(\mathrm{x}=0,0.5$ and 1) crystals in $240-310 \mathrm{~nm}$ spectral range is caused by the excited-state absorption of $\mathrm{Ce}^{3+}$ ions from $5 \mathrm{~d}$-states to $6 \mathrm{~s}$-state localized in the conduction band of these crystals.

\section{References}

1. K.-S. Lim, D.C. Hamilton, J. of Lum. 40-41 P. 319-320 (1988)

2. C. Pedrini, D.S. McClure, C.H. Anderson, J. Chem. Phys. 70 P. 4959-4962 (1979)

3. M.-F. Joubert, S.A. Kazanskii, Y. Guyot, J.-C. Gacon, C. Pedrini, Phys. Rev. B. 69165217 (2004)

4. V.V. Semashko, Phys. Solid State. 47 P. 1507 (2005) 